\title{
EVALUATION OF ERTS-I IMAGERY FOR INVENTORY WORK OF PERENNIAL SNOW PATCHES IN GENTRAL JAPAN
}

\author{
By Keiji Higuchi \\ (Water Research Institute, Nagoya University, Nagoya, Japan)
}

\begin{abstract}
In order to make the inventory of perennial snow patches in central Japan as a part of the I.H.D. world inventory of perennial ice and snow masses, observations have been continued by the author and collaborators by taking photographs of snow patches from the air every autumn since I 968 . The results obtained during the period from I968 to I 970 were published as the Atlas of perennial snow patches in central Japan (Higuchi and Iozawa, I97I). The flight for observation in 1972 was made on 13 October, just after 5 October 1972 when the Earth resources technology satellite (ERTS-I) imagery of central Japan was obtained. Therefore it was possible to compare the ERTS imagery of perennial snow patches in central Japan with aerial photographs of them.

The perennial snow patches can be classified as (a) snow patches developed mainly from avalanching, (b) those developed mainly from snow drifting, and (c) those developed from both. The perennial snow patches in central Japan are mainly those of types (a) and (b). Since the prevailing wind direction in winter is north-west in this area, snow drifting and also avalanching of drifted snow occur at the eastern side of the mountains running southwards from the Sea of Japan. Therefore, $65 \%$ of the perennial snow patches of type (a) and $70 \%$ of those of type (b) are located at the eastern side of mountains. Fortunately, the ERTS imagery of this area was obtained at a local time when the solar azimuth was $143^{\circ}$ so that many of the snow patches were in sunshine. Therefore, comparison of the ERTS imagery of snow patches with aircraft photographs in this case can be used as the data to discuss the limit of observation of small ice and snow masses by this satellite.

It was found from comparisons between the ERTS-I MSS imagery of band 4 (0.5 to $0.6 \mu \mathrm{m})$, band $5(0.6$ to $0.7 \mu \mathrm{m})$ and band $6(0.7$ to $0.8 \mu \mathrm{m})$ that the band 4 imagery was best to distinguish snow patches. Snow patches of type A were most clearly seen on the imagery. Since they are located in the valleys where avalanching occurs, the contrast between the white snow surface and the dark valley walls was quite clear. For instance, it was easy on the imagery to find four long snow patches (No. I2 70I, 12 708, 12718 and 12720 in the Atlas) at the eastern slope of the mountain Tsurugi Dake (2 $998 \mathrm{~m}$ above sea-level), their width being $30-50 \mathrm{~m}$ and their length $\mathrm{I} 000-\mathrm{I} 500 \mathrm{~m}$. It was difficult on the imagery to distinguish snow patches of type (b) from an exposed surface, since they are not so long as those of type (a), but circular and small. However, big ones of type (b) can be found on the imagery when they are located near ridges in the sunshine. For instance, the snow patch No. 18509 in the Atlas was seen on the imagery, its size being $200 \mathrm{~m} \times 100 \mathrm{~m}$. Snow patches of type (c) are few and this type seems most difficult to find on the imagery, since they located at the bottom of cirque valleys in the shadow.
\end{abstract}

\section{REFERENCES}

Higuchi, K., and Iozawa, T. I971. Atlas of perennial snow patches in central Japan. Nagoya, Nagoya University, Faculty of Science, Water Research Laboratory. 